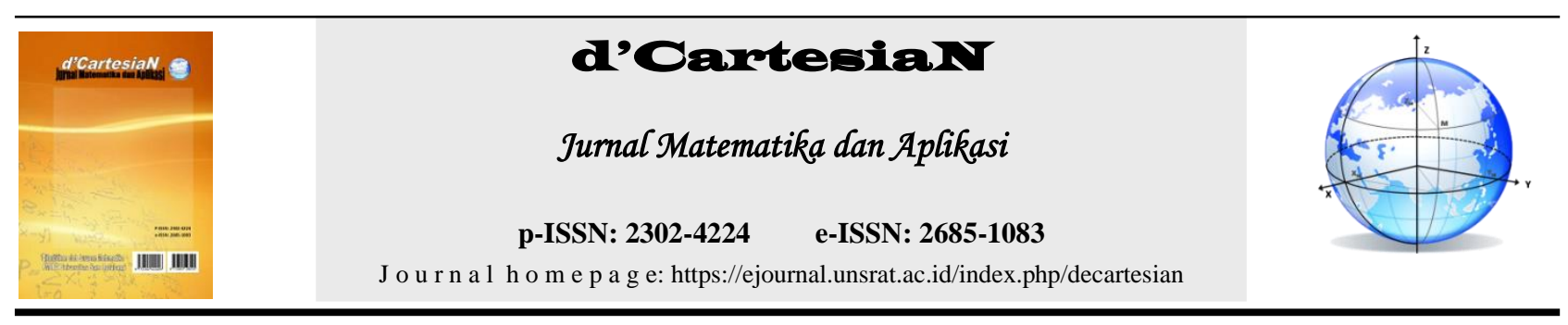

\title{
Penerapan Geometri Fraktal Dalam Membuat Variasi Motif Batik Nusantara Berbasis Julia Set
}

\author{
Fernando Y. Solar ${ }^{1}$, Jullia Titaley ${ }^{*}$, Altien J. Rindengan' ${ }^{1}$ \\ ${ }^{1}$ Jurusan Matematika-Fakultas Matematika dan Ilmu Pengetahuan Alam-Universitas Sam Ratulangi Manado, Indonesia \\ ${ }^{*}$ Corressponding author : july titaley@unsrat.ac.id
}

\begin{abstract}
A B S T R A K
Julia Set adalah salah satu jenis fraktal yang berkaitan dengan bilangan kompleks dan dibangkitkan dari fungsi teriterasi $f_{c}(z)=z_{n}^{2}+c$. Tujuan penelitian ini adalah menerapkan geometri fraktal berbasis Julia Set dengan nilai $-2 \leq a \leq 2$ dan $-2 \leq b \leq 2$ dengan polinomial kubik untuk membuat variasi motif batik nusantara yang baru. Penelitian ini menghasilkan motif Julia Set yang dibentuk dengan menentukan nilai $c$ tertentu dan digabungkan dengan motif batik nusantara sehingga menghasilkan motif batik nusantara berbasis Julia set.
\end{abstract}

INFO ARTIKEL:

Diterima : 7 Agustus 2020

Diterima setelah revisi : 31 Agustus 2020

Tersedia online : 6 Januari 2021

\section{Kata Kunci:}

Fraktal

Julia Set

Batik Nusantara

\section{A B S T R A C T}

Julia Set is a type of fractal that deals with complex numbers and is generated from the iterated $f_{c}(z)=z_{n}^{2}+c$. The aim of this research is to apply a fractal geometry based on Julia Set with values $-2 \leq a \leq 2$ and $2 \leq b \leq 2$ with cubic polynomials to create a variety of new Indonesian batik motifs. This research produces the Julia Set motif which is formed by determining a certain c value and is combined with the Nusantara batik motif to produce the Nusantara batik motif based on the Julia set.

\section{ARTICLE INFO:}

Diterima : 7 August 2020

Diterima setelah revisi : 31 August 2020

Tersedia online : 6 January 2021

\section{Keywords:}

Fraktal

Julia Set

Nusantara Batik

\section{PENDAHULUAN}

Matematika adalah ilmu yang dipelajari untuk membantu menyelesaikan permasalahan yang dihadapi manusia. Secara sadar ataupun tidak sadar kita mengetahui bahwa alam berkaitan erat dengan matematika. Matematika dapat di temukan di alam. Salah satu cabang matematika yang berkaitan dengan alam adalah geometri [3].

Seiring berkembangnya geometri muncullah beberapa gagasan, seperti gagasan Geometri Eucluid dan Geometri Non-Euclid. Geometri Non-Euclid merupakan gagasan yang bertentangan dengan Geomotri Euclid, salah satu contoh gagasan Geometri Non-Euclid adalah Geometri Fraktal. Teori fraktal adalah suatu pendekatan untuk mengukur bentuk atau menggambarkan kompleksitas obyek atau untuk menggambarkan variasi fitur yang tidak teratur [2]. Hal yang sangat penting dari karakteristik fraktal adalah dimensinya, dimana dimensi tersebut menunjukkan derajat dari kompleksitasnya. Karena konsep fraktal yang berasal dari pendekatan geometris, maka analisis fraktal dari geometris obyek menjadi sangat natural dan kita dapat menentukan estimasi dimensi fraktal berdasarkan pendekatan geomeatris [6].
Berbagai jenis fraktal pada awalnya dipelajari sebagai benda-benda matematis. Ada banyak bentuk matematis yang merupakan fraktal, antara lain Sierpinski triangle, Koch snowflake, Peano curve, Mandelbrot set, dan Julia set. Julia set dapat dibangkitkan menggunakan software dengan pengiterasian fungsi $f_{n+1}(z)=z_{n}^{2}+c$ dan penentuan parameter $c \in \mathbb{C}$ sehingga $c=a+b i$ dimana $a, b \in \mathbb{R}$. pengolahan ragam hias asli beserta Julia set dapat diolah menggunakan aplikasi perangkat lunak basis fraktal, sehingga penelitian ini dillakukan untuk menemukan pola baru dari Julia set.

Kodri dan Titaley (2017), melakukan penelitian tentang menggabungkan variasi motif batik khas minahasa dengan variasi motif baru yang berbasis Julia Set dan hasilnya menunjukan bahwa dengan memilih bilangan kompleks $c=a+b i$ dengan nilai $-2 \leq a \leq 2$ dan $-2 \leq b \leq 2$ dapat menghasilkan motif Julia set yang menarik. Penelitian selanjutnya tentang mencari kelas baru Julia set dengan fungsi polinomial kubik dan kuadratik dengan fungsi sinus dan kosinus secara teoritis dan hasil akhirnya adalah menemukan inovatif baru dari Julia Set dengan menggunakan fungsi trigonometri [8]. 
Dari latar belakang diatas, maka akan dilakukan penelitian tentang menggabungkan variasi batik nusantara dengan motif baru Julia Set dengan fungsi polinomial kubik untuk mendapatkan variasi batik nusantara yang baru.

\section{TINJAUAN PUSTAKA}

\subsection{Fraktal}

Fraktal berasal dari kata fractus, kata bersifat dalam bahasa latin yang bersesuaian dengan kata kerjanya frangere yang berarti pecah, untuk menciptakan potongan potongan yang tidak beraturan. Fraktal adalah suatu kajian dalam ilmu matematika yang mempelajari mengenai bentuk atau geometri yang di dalamnya menunjukan sebuah proses pengulangan tanpa batas. Geometri yang di lipat gandakan tersebut memiliki kemiripan bentuk satu sama lain (Self similiarity), dan penyusunan pelipat-gandaannya tersebut tidak terikat pada satu orientasi, bahkan cenderung meliuk-liuk dengan ukuran yang beragam mulai dari kecil hingga besar. Berbagai jenis fractal awalnya dipelajari sebagai benda-benda matematis [5].

Sifat Self-Similarity ada dua macam fraktal yaitu Reguler Fractal dan Random Fractal. Reguler Fractal mempunyai sifat exactly self-similarity yaitu setiap bagian dari objek fraktal menyerupai secara persis dengan bentuk objek secara keseluruhan jika dilihat dalam berbagai skala. Contoh objek fraktal yang mempunyai sifat exactly self-similarity adalah truktur daun pakis, egitiga Sierpinski, Himpunan cator. Sedangkan Random Fractal mempunyai sifat statiticaly self-similarity adalah Julia Set set dan madelbrot [1].

\subsection{Julia Set}

Julia Set merupakan objek fraktal acak atau disebut sebagai random fractal yang dibentuk dengan memberi batasan-batasan daerah yang digunakan untuk menggambarnya. Ada dua bagian di dalam Julia Set yaitu Julia Set itu sendiri dan Julia Set yang merupakan himpunan filled-in Julia. Julia Set merupakan cakram terbuka yang mempunyai keserupaan bentuk pada setiap bagian objek-objeknya sampai dengan perbesaran tak hingga [4].

Julia Set ditemukan oleh Gaston Julia merupakan fraktal dimensi dua yang berkaitan dengan bilangan kompleks. Julia Set dibangkitkan dari pemetaan fungsi teriterasi $\boldsymbol{f}_{c}(\mathbf{z}): \mathbb{C} \rightarrow \mathbb{C}$ yang didefinisikan :

$$
f_{c}(z)=z_{n}^{2}+c
$$

Dimana $\boldsymbol{z}, \boldsymbol{c} \in \mathbb{C}$ dan $\boldsymbol{c}$ adalah konstanta. Barisan bilangan kompleks $\boldsymbol{z}, \boldsymbol{f}_{\boldsymbol{c}}(\mathbf{z}), \boldsymbol{f}_{\boldsymbol{c}}{ }^{2}(\mathbf{z}), \ldots, \boldsymbol{f}_{\boldsymbol{c}}{ }^{\boldsymbol{n}}(\mathbf{z})$, yang terbentuk disebut orbit [8].

\subsection{Batik Nusantara}

Batik merupakan hal yang tidak asing bagi masyarakat Indonesia saat ini, batik merupakan salah satu warisan nusantara yang unik, keunikannya ditunjukkan dengan barbagai macam motif yang memiliki makna tersendiri, berdasarkan etimologi dan terminologinya, batik merupakan rangkaian kata mbat dan tik. Mbat dalam bahasa Jawa dapat diartikan sebagai ngembat atau melempar berkali-kali, sedangkan tik berasal dari kata titik. Jadi, membatik artinya melempar titik berkali-kali pada kain. Adapula yang mengatakan bahwa kata batik berasal dari kata amba yang berarti kain yang lebar dan kata titik. Artinya batik merupakan titik-titik yang digambar pada media kain yang lebar sedemikian sehingga menghasilkan pola-pola yang indah. Dalam Kamus Besar Bahasa Indonesia, batik memiliki arti kain bergambar yang pembuatannya secara khusus dengan menuliskan atau menerakan malam pada kain itu, kemudian pengolahannya diproses dengan cara tertentu .

\section{HASIL DAN PEMBAHASAN}

\subsection{Mengubah Bentuk Umum Julia Set Dari Kuadratik Menjadi Kubik.}

Titaley at al (2018) telah melakukan pembuktian untuk mengubah bentuk umum Julia Set dari Kuadratik menjadi Kubik dengan mengandaikan $f(z)$ mempunyai titik tentu pada $z$, maka $z$, adalah :

- Attracting jika $0<\left|f^{\prime}\left(z_{0}\right)\right|<1$

- Repelling jika $\left|f\left(z_{0}\right)\right|>1$,

- Neutral jika $\left|f^{\prime}\left(z_{0}\right)\right|=1$.

untuk polinomial kuadrat kompleks $f_{c}(z)=z^{2}+a z+c$, dipilih $T_{c} z=z^{2}+c$ dan $z^{\prime}=a z$ dimana $a$ dan $c$ adalah bilangan kompleks.

Teorema 1. Di asumsikan bahwa $|z| \geq|c|>$ $2(1+|a|) / \alpha,|z| \geq|c|>2(1+|a|) / \beta$, dan $|z| \geq|c|>$ $2(1+|a|) / \gamma$, dimana $0<\alpha, \beta, \gamma<1$ dan $a, c$ adalah bilangan kompleks. Maka ada $\lambda>0$, sehingga $\left|z_{1}\right|>(1$ $+\lambda)|z|$ dan $\left|z_{n}\right|>(1+\lambda)^{n}|z|$, untuk $n>1$.

Teorema 2. Misalkan ada $|z|>|c|>2(1+|a|) / \alpha)^{1 / 2}$, $|z|>|c|>(2(1+|a|) / \beta)^{1 / 2}$

$|z|>|c|>2(1+|a|) / \gamma)^{1 / 2}$, dimana $0<\alpha, \beta, \gamma<1$ dan $a$, $c$ adalah bilangan kompleks. Kemudian ada $\lambda>0$, menunjukan $\left|z_{1}\right|>(1+\lambda)|z|$ dan $\left|z_{n}\right|>(1+\lambda)^{n}|z|$, untuk $n>1$.

\subsection{Membuat Motif Julia Set}

Untuk kombinasi yang pertama Julia set dengan $\mathrm{c}=-2$ menunjukan Julia set yang berbentuk tiga titik yang membentuk segitiga (lihat gambar 1 (a)). nilai $a<$ -2 maka titik yang membentuk setigita semakin menjauh dan pada nilai tertentu titik yang berbentuk segitiga tidak akan kelihatan (lihat gambar 1(b).

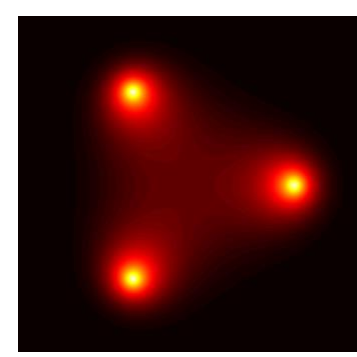

(a) Julia Set, $c=-2$

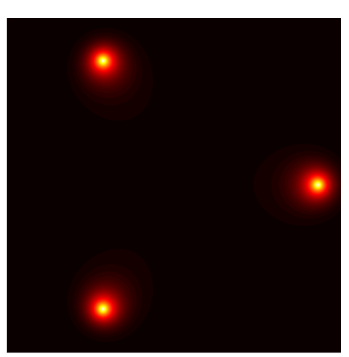

(b) Julia Set, $c=-5$
Gambar 1. Julia Set 1

Julia set dengan nilau $-2<a \leq-0.5$ menunjukan Julia set yang bentuk titiknya semakin menebal dan bergelombang membentuk daun yang semakin membesar hingga pada $-0.5<a<0$ Julia Set mulai menyatu dan menebal mendekati bentuk lingkaran (lihat gambar 2). 


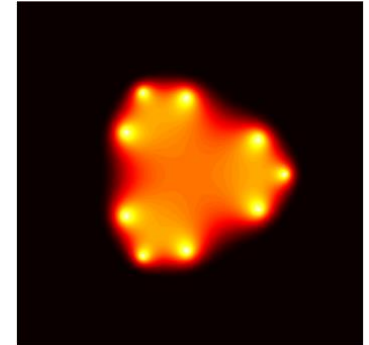

(a) Julia set, $c=-1.5$

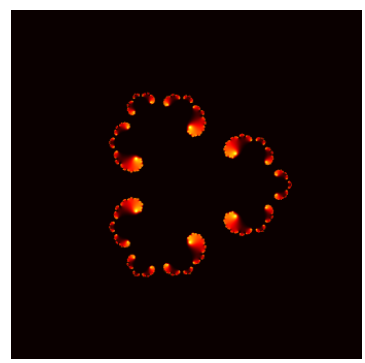

(c) Julia set, $c=-0.7$

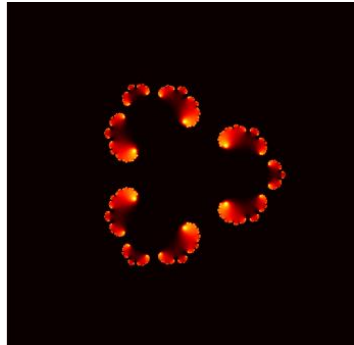

(b) Julia set, $c=-0.9$

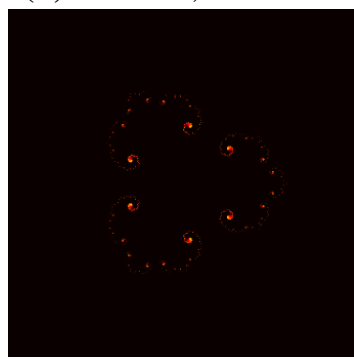

(e) Julia set, $c=-0.3$
Gambar 2. Julia Set 2

Pada $c=0$ berbentuk lingkaran berjari-jari 1, setelah itu sebaliknya pada $0<a \leq 2$ lingkaran yang tadinya sempurna mulai membentuk bentuk yang tidak simetris, titik titik yang ada mulai menyebar (lihat gambar 3).

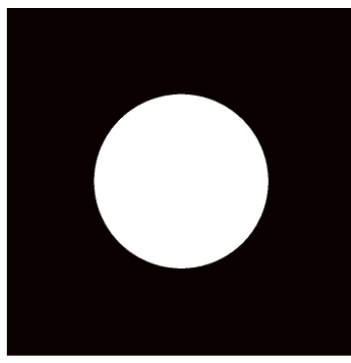

(a) Julia Set c $=0$

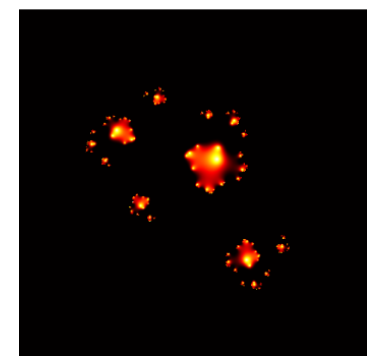

(b) Julia Set c $=0.5$
Gambar 3. Julia Set 3.

Untuk kombinasi yang kedua Julia Set dengan nilai $c=-2$ menunjukkan Julia set yang berbentuk titik-titik dan terbagi di kiri dan kanan tetapi tidak horizontal, titik-titik tersebut menebal sehingga yang tadinya tidak terhubung menjadi terhubung ketika $c=$ $1 i$ (gambar 4).

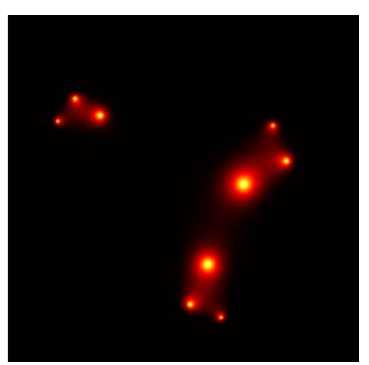

(a) Julia Set $c=-2 i$

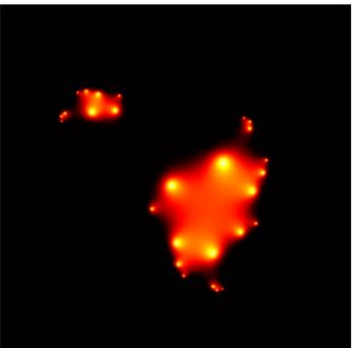

(b) Julia Set c $=-1 i$
Gambar 4. Julia Set 4.

Dari semua motif Julia Set yang dibuat, penulis memilih beberapa motif Julia set yang menurut penulis menarik dengan nilai c berdasarkan bentuk yang dipilih (lihat gambar 5). Dari semua Julia Set yang dipilih, dapat disimpulkan bahwa jika nilai yang diambil dalam range $-2 \leq a \leq 2$ dan $-2 \leq b \leq 2$ semakin mendekati nol maka menurut penulis motif Julia Set yang dihasilkan akan lebih menarik.
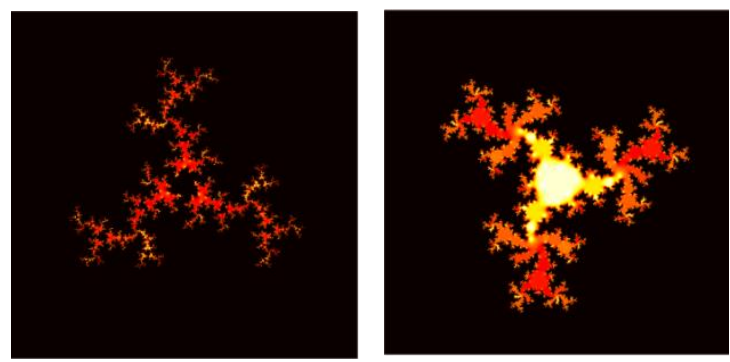

(a). $c=-0.561321+0.6410000 \mathrm{i}$

(b). $c=-0.38765765-0.68754 \mathrm{i}$
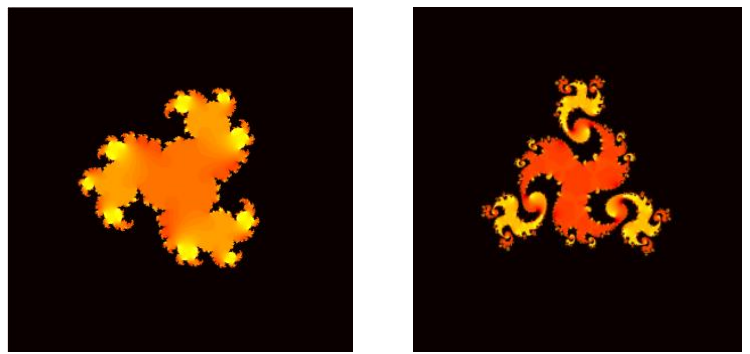

(c). $c=0.5+0.1 \mathrm{i}$

(d). $c=0.1+0.789 \mathrm{i}$

Gambar 5. Motif Julia Set

\subsection{Motif Batik Nusantara Dipilih}

Pada penelitian ini dipilih beberapa jenis motif batik tradisional nusantara (seperti gambar 6) yang terdiri dari :

a. Ragam hias bulu burung Cendrawasih

b. Ragam hias burung Mambtruk Papua

c. Ragam hias bulu burung Kuau Kalimantan

d. Ragam hias tanaman Bambu

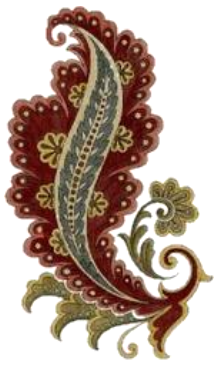

(a)

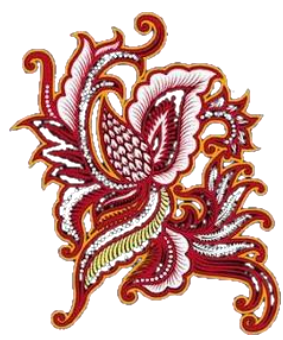

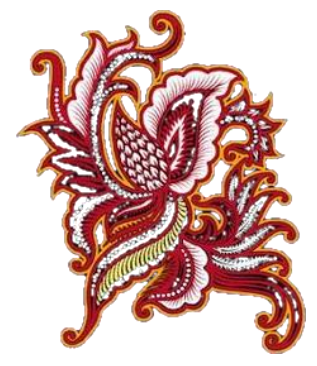

(b)

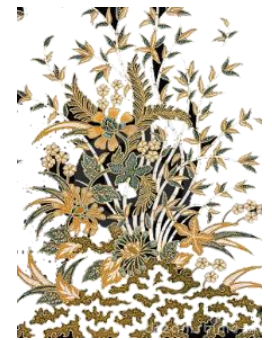


Fernando Y. Solar, Jullia Titaley, Altien J. Rindengan.

d'Cartesian : Jurnal Matematika dan Aplikasi, Vol. 9, No.2 (September 2020): 189-193

(c)

(d)

\subsection{VaciansibafGifMdatthtiNNsantara Berbabsis Julia Set}

Penelitian ini menghasilkan 2 variasi motif batik Nusantara berbasis Julia set. Variasi pertama dibuat dengan 4 jenis motif Julia set dan 2 motif tradisional nusantara. Pemilihan warna latar berdasarkan warna motif Julia set yang dibuat dan untuk pemilihan warna pada motif tradisional nusantara berdasarkan dominan warna yang cocok pada motif Julia Set.

Hasil akhir variasi motif batik Nusantara berbasis Julias set yang pertama ditampilkan pada gambar 7 dan variasi motif batik Nusantara berbasis Julia Set yang kedua ditampilkan pada gambar 8. Penggabungan antara motif Julia Set dengan motif batik nusantara menggunakan aplikasi Software Photo Editor.

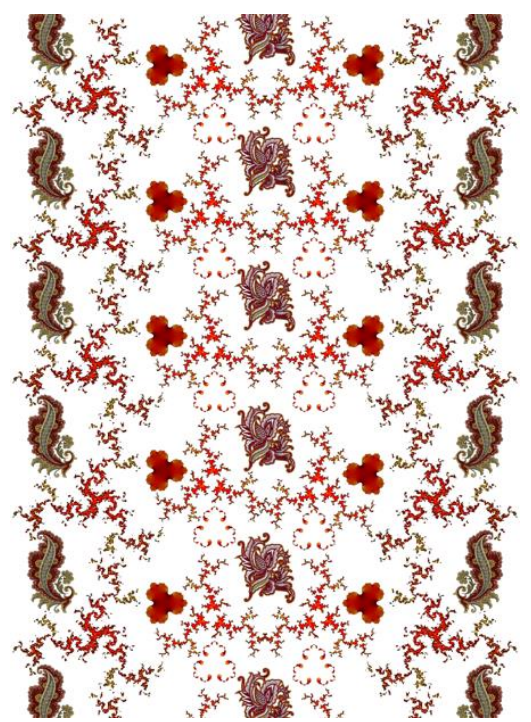

Gambar 7. Variasi motif batik Nusantara berbasis Julia set (1)

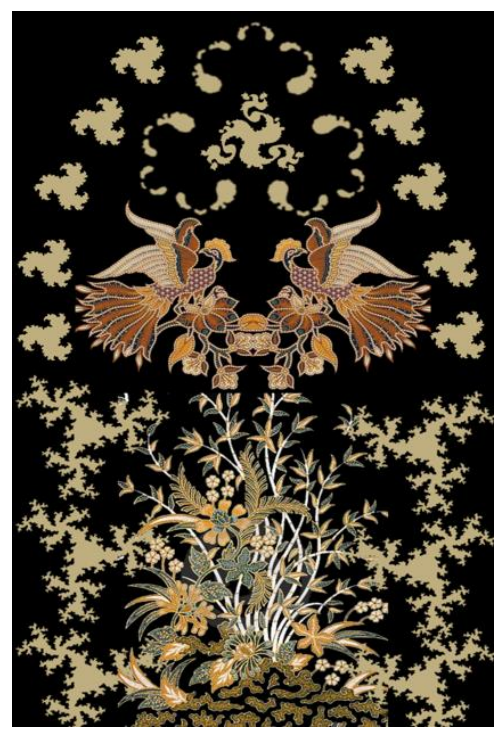

Gambar 8. Variasi motif batik Nusantara berbasis Julia set (2)

\section{Penutup}

\subsection{Kesimpulan}

Berdasarkan hasil penelitian yang diperoleh, dapat disimpulkan bahwa Motif Julia Set dapat dibentuk dengan menentukan nilai $c$ sebuah bilangan kompleks dengan range $-2 \leq a \leq 2$ dan $-2 \leq b \leq 2$ dalam polinomial kubik. Dalam penelitian ini dapat disimpulkan bahwa jika nilai yang diambil dalam range $-2 \leq a \leq 2$ dan $-2 \leq b \leq 2$ semakin mendekati nol maka motif Julia Set yang dihasilkan akan lebih menarik.

\subsection{Saran}

Saran dari penelitian ini yaitu dapat dikembangkannya aplikasi software untuk menunjang perkembangan matematika dalam design grafis,

\section{REFERENSI}

[1] Addison, P. S. 1997. Fractal and chaos. Bristol and Piladhelphia. Institude of Physich Publishing.

[2] Burrough, P.A., and R. A. McDonell. 1998. Principles of Geographical Information System. Oxford University Press. New York.

[3] Burton, D. M. 2011. The History of Mathematic : An Introduction : Seventh Edition. McGraw-Hill. New York.

[4] Falconer, K., 1992. Fractal Geometry : Mathematical Foundation \& Applications. John Wiley \& Sons,Inc. New York.

[5] Hasang, S., dan Supardjo, S. 2012. Geometri Fraktal dalam Rancangan Arsitektur. Media Matrassain. 9(1) : 111 - 116.

[6] Kinsner, W. 1994. Fractal Dimension Morphology Entropy Spectrum and Variance Classer. Technical Report. Departement of Electrical Engineering. University of Manitoba.

[7] Muwarni, T. 2011. Dimensi Fraktal Julia Set. [Skripsi]. FMIPA Universitas Sanatha Dharma. Yogyakarta.

[8] Titaley, J., T. Manurung., dan H. T. Titaley. 2018. Cubic and Quardratic Polynomial On Julia Set With Trigonometric Function. Jurnal Ilmiah Sains 18(2) : 104 - 106. 


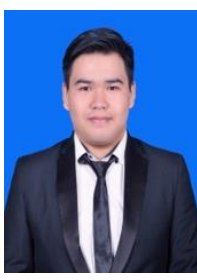

\section{Fernando Y. Solar}

(Fernandosolar27@gmail.com)

Lahir di Langowan, Sulawesi Utara pada tanggal o7 Februari 1999. Menempuh pendidikan tinggi Jurusan Matematika, FMIPA, Universitas Sam Ratulangi Manado. Tahun 2020 adalah tahun terakhir ia menempuh studi. Makalah ini merupakan hasil penelitian skripsinya yang dipublikasikan.

\section{Jullia Titaley (july titaley@unsrat.ac.id)}

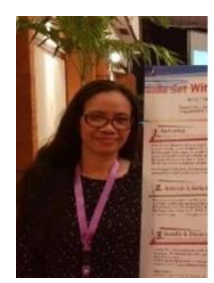

Pada tahun 1996 memperoleh gelar Sarjana di Program Studi Pendidikan Matematika, Universitas Pattimura Ambon. Gelar Magister Saing diperoleh dari Universitas Gajah Mada pada tahun 2001. Menjadi Dosen di Jurusan Matematika, Fakultas Matematika dan ilmu Pengetahuan Alam, Universitas Sam Ratulangi Manado sejak 2000 sampai sekarang dengan bidang keahlian yang ditekuni diantaranya: Analisis, Aljabar, dan geometri.

Altien J. Rindengan (altien@unsrat.ac.id)

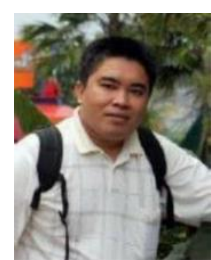

Pada tahun 1999 memperoleh gelar Sarjana di Departemen Matematika, Fakultas Matematikan dan Ilmu Pengetahuan Alam, Institut Pertanian Bogor. Gelar Magister Ilmu Komputer diperoleh dari Departemen Ilmu Komputer, Institut Pertanian Bogor, pada tahun 2012. Sejak tahun 2001 menjadi pengajar di jurusan Matematika, Fakultas Matematika dan Ilmu Pengetahuan Alam, Universitas Sam Ratulangi Manado. Fokus penelitian-penelitian yang dilakukan adalah Riset Operasi, Sistem Pendukung Keputusan, Sistem Fuzzy, Image Proccesing. 